\title{
Relationship between ventilator-associated pneumonia and mortality in COVID-19 patients: a planned ancillary analysis of the coVAPid cohort
}

Saad Nseir ${ }^{1,2^{*}} \mathbb{0}$, Ignacio Martin-Loeches ${ }^{3,4}$, Pedro Povoa ${ }^{5,6}$, Matthieu Metzelard ${ }^{7}$, Damien Du Cheyron ${ }^{8}$, Fabien Lambiotte ${ }^{9}$, Fabienne Tamion $^{10}$, Marie Labruyere ${ }^{11}$, Demosthenes Makris ${ }^{12}$, Claire Boulle Geronimi ${ }^{13}$, Marc Pinetonde Chambrun ${ }^{14}$, Martine Nyunga ${ }^{15}$, Olivier Pouly ${ }^{16}$, Bruno Mégarbane ${ }^{17}$, Anastasia Saade ${ }^{18}$, Gemma Gomà ${ }^{19}$, Eleni Magira ${ }^{20}$, Jean-François Llitjos ${ }^{21}$, Antoni Torres ${ }^{22}$, Iliana loannidou ${ }^{23}$, Alexandre Pierre ${ }^{24}$, Luis Coelho ${ }^{5}$, Jean Reignier ${ }^{25}$, Denis Garot ${ }^{26}$, Louis Kreitmann ${ }^{27}$, Jean-Luc Baudel ${ }^{28}$, Guillaume Voiriot ${ }^{29}$, Damien Contou ${ }^{30}$, Alexandra Beurton ${ }^{31}$, Pierre Asfar ${ }^{32}$, Alexandre Boyer ${ }^{33}$, Arnaud W. Thille ${ }^{34}$, Armand Mekontso-Dessap ${ }^{35}$, Vassiliki Tsolaki ${ }^{12}$, Christophe Vinsonneau ${ }^{36}$, Pierre-Edouard Floch ${ }^{37}$, Loïc Le Guennec ${ }^{38}$, Adrian Ceccato ${ }^{39}$, Antonio Artigas ${ }^{40}$, Mathilde Bouchereau', Julien Labreuche ${ }^{41}$, Alain Duhamel ${ }^{41}$ and Anahita Rouzé ${ }^{1,2}$ the coVAPid study group

\begin{abstract}
Background: Patients with SARS-CoV-2 infection are at higher risk for ventilator-associated pneumonia (VAP). No study has evaluated the relationship between VAP and mortality in this population, or compared this relationship between SARS-CoV-2 patients and other populations. The main objective of our study was to determine the relationship between VAP and mortality in SARS-CoV-2 patients.

Methods: Planned ancillary analysis of a multicenter retrospective European cohort. VAP was diagnosed using clinical, radiological and quantitative microbiological criteria. Univariable and multivariable marginal Cox's regression models, with cause-specific hazard for duration of mechanical ventilation and ICU stay, were used to compare outcomes between study groups. Extubation, and ICU discharge alive were considered as events of interest, and mortality as competing event.
\end{abstract}

Findings: Of 1576 included patients, 568 were SARS-CoV-2 pneumonia, 482 influenza pneumonia, and 526 no evidence of viral infection at ICU admission. VAP was associated with significantly higher risk for 28-day mortality in SARS-CoV-2 group (adjusted HR 1.65 (95\% Cl 1.11-2.46), $p=0.013$ ), but not in influenza (1.74 (0.99-3.06), $p=0.052$ ), or no viral infection groups $(1.13(0.68-1.86), p=0.63)$. VAP was associated with significantly longer duration of mechanical ventilation in the SARS-CoV-2 group, but not in the influenza or no viral infection groups. VAP was associated with significantly longer duration of ICU stay in the 3 study groups. No significant difference was found in heterogeneity

*Correspondence: s-nseir@chru-lille.fr

${ }^{1}$ Médecine Intensive-Réanimation, CHU de Lille, F-59000 Lille, France

Full list of author information is available at the end of the article International License, which permits use, sharing, adaptation, distribution and reproduction in any medium or format, as long as you give appropriate credit to the original author(s) and the source, provide a link to the Creative Commons licence, and indicate if changes were made. The images or other third party material in this article are included in the article's Creative Commons licence, unless indicated otherwise in a credit line to the material. If material is not included in the article's Creative Commons licence and your intended use is not permitted by statutory regulation or exceeds the permitted use, you will need to obtain permission directly from the copyright holder. To view a copy of this licence, visit http://creativecommons.org/licenses/by/4.0/. The Creative Commons Public Domain Dedication waiver (http://creativecommons.org/publicdomain/zero/1.0/) applies to the data made available in this article, unless otherwise stated in a credit line to the data. 
of outcomes related to VAP between the 3 groups, suggesting that the impact of VAP on mortality was not different between study groups.

Interpretation: VAP was associated with significantly increased 28-day mortality rate in SARS-CoV-2 patients. However, SARS-CoV-2 pneumonia, as compared to influenza pneumonia or no viral infection, did not significantly modify the relationship between VAP and 28-day mortality.

Clinical trial registration: The study was registered at ClinicalTrials.gov, number NCT04359693.

Keywords: Ventilator-associated pneumonia, Mortality, COVID-19

\section{Background}

Coronavirus disease-19 (COVID-19) pandemic is ongoing, and several million patients have been hospitalized in intensive care units (ICUs) worldwide. A large percentage of COVID-19 patients admitted to the ICU require invasive mechanical ventilation, and are at higher risk for ventilator-associated pneumonia (VAP) [1]. In the large multicenter European coVAPid study [2], SARS$\mathrm{CoV}-2$ infection was associated with higher risk for VAP, and ventilator associated tracheobronchitis (VAT), as compared to patients with influenza, or no viral infection at ICU admission. Other recent studies [3-7] confirmed these results and reported a high incidence of VAP ranging from 44 to $86 \%$. This could be explained by the prolonged duration of mechanical ventilation in these patients, high rate of acute respiratory distress syndrome (ARDS), common use of corticosteroids, and perhaps specific factors related to severe acute respiratory syndrome Coronavirus 2 (SARS-CoV-2) infection.

Several studies, performed in general ICU populations and using different methods, showed higher mortality rates, and longer duration of mechanical ventilation and ICU stay in VAP patients, as compared with those with no VAP [8-13]. To our knowledge, no study to date has specifically addressed the effect of VAP on mortality in SARS-CoV-2 patients, or the impact of SARS-CoV-2 infection on the relationship between VAP and mortality. Therefore, we conducted this planned ancillary study of the coVAPid European multicenter cohort to determine the impact of VAP on mortality in SARS-CoV-2 patients. We also aimed to determine the impact of SARS-CoV-2 pneumonia, as compared with influenza pneumonia or no viral infection at ICU admission, on the relationship between VAP and mortality.

\section{Methods}

\section{Study design and population}

This study is a planned ancillary analysis of the coVAPid cohort study. Briefly, coVAPid was a multicenter retrospective observational European cohort study. Eligibility criteria included age equal or above 18 years, the need for invasive mechanical ventilation for more than $48 \mathrm{~h}$, and one of the following criteria at ICU admission: (1)
SARS-CoV-2 pneumonia, (2) influenza (A or B) pneumonia, or (3) no viral infection.

The Ethics Committee, and Institutional Review Boards approved the study protocol (Comité de Protection des Personnes Ouest VI; approved by April 14, 2020; registration number RIPH:20.04.09.60039) as minimal-risk research using data collected for routine clinical practice, and waived the requirement for informed consent. The study was registered at ClinicalTrials.gov, number NCT04359693.

SARS-CoV-2 infection was confirmed by positive polymerase chain reaction (PCR) testing of a nasopharyngeal or respiratory secretions samples. Influenza pneumonia was diagnosed based on a positive nasopharyngeal or airway secretions PCR test.

\section{Definitions}

\section{Ventilator-associated lower respiratory tract infection}

The diagnosis of VA-LRTI was based on the presence of at least two of the following criteria: body temperature of more than $38.5{ }^{\circ} \mathrm{C}$ or less than $36.5^{\circ} \mathrm{C}$, leucocyte count greater than 12,000 cells per $\mu \mathrm{L}$ or less than 4000 cells per $\mu \mathrm{L}$, and purulent tracheal secretions [14, 15]. Additionally, all episodes of infection needed microbiological confirmation, with the isolation in the endotracheal aspirate of at least $10^{5}$ colony-forming units (CFU) per mL, or in bronchoalveolar lavage of at least $10^{4} \mathrm{CFU}$ per mL. VAT was defined with the above-mentioned criteria with no radiographic signs of new pneumonia. VAP was defined by the presence of new or progressive infiltrates on chest $\mathrm{X}$-ray. Only first episodes of VAT and VAP occurring more than $48 \mathrm{~h}$ after starting invasive mechanical ventilation were analyzed. All VA-LRTI episodes were prospectively identified, and chest X-rays were reviewed by at least two attending physicians. In case of disagreement, a third physician was asked to interpret the radiograph. Late-onset VAP was defined as VAP diagnosed after 4 days of invasive mechanical ventilation [15]. Initial antibiotic treatment was considered as appropriate when at least one antibiotic, matching the in vitro susceptibility of the pathogen causing VAP, was given to treat this infection [16]. 


\section{Outcomes}

The primary outcome of this ancillary study was 28-day all-cause mortality. Secondary outcomes included duration of mechanical ventilation, and ICU length of stay censored at 28 days.

\section{Statistical analysis}

Quantitative variables were expressed as medians (interquartile range) and categorical variables were expressed as numbers (percentage). Patient characteristics at ICU admission and during ICU stay were described according to study disease groups (SARS-CoV-2 pneumonia vs. Influenza pneumonia vs. no viral infection) without formal statistical comparisons. Patient's outcomes (overall survival, mechanical ventilation duration, length of ICU stay) were described according to study disease groups using survival analysis approach by estimating the cumulative incidence of event of interest (death, extubation alive and ICU discharge alive) censored at 28-days. Cumulative incidence of death was estimated using Kaplan-Meier method, cumulative incidence of extubation alive and ICU discharge alive were estimated using Kalbfleisch and Prentice method, considering death as competing event [17].

We assessed the effect of SARS-CoV-2 pneumonia compared to the two other disease groups on patient's outcomes using a univariable and multivariable marginal Cox's regression models to account clustered (center) data, with cause-specific hazard for mechanical ventilation duration and length of ICU stay (considering extubation alive and ICU discharge alive as event of interest, and death as competing event). Pre-specified potential predictors of patient outcomes (age, gender, SAPS II, Charlson score, McCabe classification, shock and ARDS) were included as covariates into multivariable models. Hazard ratios (HRs) for SARS-CoV-2 pneumonia vs. Influenza pneumonia, and HRs for SARS-CoV-2 pneumonia vs. no viral infection were derived from Cox's models as effect size. A HR $>1$ indicates a decrease in survival, mechanical ventilation duration and length of ICU stay, whereas a $\mathrm{HR}<1$ indicates an increase in survival, mechanical ventilation duration and length of ICU stay.

In each disease group, we assessed the association of first episodes of VA-LRTI with patient's outcomes using univariable and multivariable marginal Cox's regression models, with cause-specific hazard for mechanical ventilation duration and length of ICU stay and by considering the first VA-LRTI occurrence as a time-dependent covariate (3-levels categorical variable: No VA-LRTI, vs. VAT, vs. VAP); as well as binary variable: No VA-LRTI vs. VALRTI (VAT or VAP). This model accounted for exposure time of VA-LRTI, by comparing at each follow-up time point, the current VA-LRTI status of patients who have the event to patients who are at risk (without the event of interest and without the competing event for mechanical ventilation duration and length of ICU stay) [18].

HRs associated with VAT, VAP, and no VA-LRTI were derived as effect size using time period without VA-LRTI as reference. To assess whether the association between VA-LRTI and outcomes differed between the three disease groups, a heterogeneity test was performed [19], comparing the HRs for VA-LRTI (VAP, VAT, VAT + VAP combined) between study groups.

To avoid case-deletion in multivariate analyses due to presence of missing data in covariates, multivariable Cox's models were performed after handling missing data on covariates by using multiple imputation procedure [20]. This imputation was performed using regression-switching approach (chained equations with $\mathrm{m}=20$ obtained) under the missing at random assumption using all baseline characteristics (see Table 1), disease group and outcomes (event status and log of event time), with a predictive mean matching method for quantitative variables and logistic regression model (binary, ordinal or multinomial) for categorical variables. Estimates obtained in the different imputed data sets were combined using Rubin's rules [21].

Statistical testing was performed at the two-tailed $\alpha$ level of 0.05. Data were analyzed using the SAS software package, release 9.4 (SAS Institute, Cary, NC).

\section{Results}

\section{Patient characteristics}

In total, 1576 patients were included from March 2016 through May 2020 (568 in SARS-CoV2, 482 in influenza, and 526 in no viral infection groups). 399 (25.3\%) VAP, and 167 (10.6\%) VAT first episodes were diagnosed in study patients. 28-day mortality was $28.8 \%$ (164 of 568 patients), $22 \%$ (125 of 482 patients), and $32.9 \%$ (173 of 526 patients) in SARS-CoV-2, influenza, and no viral infection groups, respectively. Older age, higher SAPS II and SOFA score, comorbidities, septic shock, cardiac arrest, and acute kidney injury rates at ICU admission were more common in non-survivors, as compared to survivors in the 3 study groups. During ICU stay, percentage of patients who received corticosteroids, prone positioning, and ECMO was higher in non-survivors as compared to survivors. The characteristics of study patients are presented in Tables 1 , and 2.

The cumulative incidence of 28-day mortality, extubation alive, and ICU discharge alive, according to study groups, are presented in Additional file 1: Fig. 1. SARSCoV-2 infection was associated with significantly longer duration of mechanical ventilation, as compared to influenza and no viral infection groups (Fig. 1). SARS-CoV-2 
Table 1 Patient characteristics at ICU admission according to disease group, and 28-day mortality

\begin{tabular}{|c|c|c|c|c|c|c|}
\hline & \multicolumn{2}{|c|}{ SARS-CoV-2 pneumonia } & \multicolumn{2}{|c|}{ Influenza pneumonia } & \multicolumn{2}{|l|}{ No viral infection } \\
\hline & Alive $(n=402)$ & Dead $(n=166)$ & Alive $(n=350)$ & Dead $(n=132)$ & Alive $(n=344)$ & Dead $(n=182)$ \\
\hline Age, years ${ }^{a}$ & $62(53-70)$ & $70(62-78)$ & $61(52-70)$ & $65(54-72)$ & $63(52-72)$ & $70(60-76)$ \\
\hline Men & 281/402 (69.9) & $126 / 166(75.9)$ & $219 / 350(62.6)$ & $79 / 131(60.3)$ & 239/342 (69.9) & $114 / 182(62.6)$ \\
\hline Body mass index, $\mathrm{kg} / \mathrm{m}^{2 \mathrm{~b}}$ & $28.7(25.5-33.6)$ & $29.1(26.0-33.0)$ & $27.5(23.1-32.3)$ & $27.6(23.5-31.7)$ & $26.3(22.7-29.8)$ & $26.9(23.2-33.3)$ \\
\hline \multicolumn{7}{|l|}{ Severity scores } \\
\hline SAPS $\|^{c}$ & $38(31-51)$ & $48(38-61)$ & $48(37-60)$ & $58(45-72)$ & $51(39-63)$ & $63(51-73)$ \\
\hline SOFA score ${ }^{d}$ & $6(3-8)$ & $7(4-10)$ & $8(5-10)$ & $10(7-13)$ & $8(5-11)$ & $9(7-12)$ \\
\hline \multicolumn{7}{|l|}{ Comorbidity scores } \\
\hline \multicolumn{7}{|l|}{ MacCabe classification } \\
\hline Non-fatal & $347 / 382(90.8)$ & 128/161 (79.5) & 249/332 (75.0) & $75 / 124(60.5)$ & 216/318 (67.9) & 99/171 (57.9) \\
\hline Fatal $<5$ years & 33/382 (8.6) & 29/161 (18.0) & 78/332 (23.5) & $36 / 124(29.0)$ & $90 / 318(28.3)$ & $47 / 171(27.5)$ \\
\hline Fatal $<1$ year & $2 / 382(0.5)$ & $4 / 161(2.5)$ & $5 / 332(1.5)$ & 13/124 (10.5) & $12 / 318(3.8)$ & 25/171 (14.6) \\
\hline Charlson Comorbidity Index & $2(1-3)$ & $4(2-5)$ & $3(2-5)$ & $4(2-6)$ & $3(2-5)$ & $5(3-6)$ \\
\hline \multicolumn{7}{|l|}{ Chronic diseases } \\
\hline Diabetes mellitus & 113/399 (28.3) & $55 / 166(33.1)$ & $72 / 344(20.9)$ & $32 / 130(24.6)$ & $82 / 338(24.3)$ & $50 / 181(27.6)$ \\
\hline Chronic renal failure & 11/395 (2.8) & 22/164 (13.4) & $25 / 346(7.2)$ & 14/129 (10.9) & $22 / 339(6.5)$ & 23/182 (12.6) \\
\hline Cardiovascular disease & $59 / 396(14.9)$ & $44 / 164(26.8)$ & $80 / 346(23.1)$ & $37 / 130(28.5)$ & $72 / 337(21.4)$ & $62 / 181(34.3)$ \\
\hline Chronic heart failure & 12/394 (3.0) & $9 / 164(5.5)$ & $19 / 345(5.5)$ & 18/130 (13.8) & $24 / 336(7.1)$ & 26/182 (14.3) \\
\hline COPD & 26/396 (6.6) & $11 / 164(6.7)$ & 96/344 (27.9) & $33 / 131(25.2)$ & $63 / 339(18.6)$ & 35/182 (19.2) \\
\hline Chronic respiratory failure & 12/394 (3.0) & 8/164 (4.9) & $56 / 344(16.3)$ & $11 / 131(8.4)$ & 28/336 (8.3) & 21/182 (11.5) \\
\hline Cirrhosis & $6 / 395(1.5)$ & $2 / 164(1.2)$ & $10 / 345(2.9)$ & 6/130 (4.6) & $18 / 335(5.4)$ & 18/181 (9.9) \\
\hline Immunosuppression & 29/395 (7.3) & 23/164 (14.0) & $61 / 348(17.5)$ & 46/131 (35.1) & $71 / 340(20.9)$ & $46 / 180(25.6)$ \\
\hline Active smoking & 20/396 (5.1) & 9/164 (5.5) & $122 / 346(35.3)$ & 27/130 (20.8) & $102 / 337(30.3)$ & $35 / 182(19.2)$ \\
\hline Alcohol abuse & 29/394 (7.4) & $5 / 164(3.0)$ & $65 / 345(18.8)$ & 20/130 (15.4) & $89 / 337(26.4)$ & 43/182 (23.6) \\
\hline \multicolumn{7}{|l|}{ Location before ICU admission } \\
\hline Home & $187 / 402(46.5)$ & $84 / 166(50.6)$ & $212 / 349(60.7)$ & $63 / 132(47.7)$ & 180/344 (52.3) & $85 / 182(46.7)$ \\
\hline Hospital ward & $154 / 402(38.3)$ & $61 / 166(36.7)$ & $104 / 349(29.8)$ & $53 / 132(40.2)$ & $147 / 344(42.7)$ & 83/182 (45.6) \\
\hline Another ICU & $61 / 402(15.2)$ & $21 / 166(12.7)$ & $33 / 349(9.5)$ & 16/132 (12.1) & 17/344 (4.9) & 14/182 (7.7) \\
\hline \multicolumn{7}{|l|}{ Admission category } \\
\hline Medical & 401/402 (99.8) & $166 / 166(100.0)$ & $348 / 350(99.4)$ & 132/132 (100.0) & 302/344 (87.8) & 165/182 (90.7) \\
\hline Surgical & $0 / 402(0.0)$ & $0 / 166(0.0)$ & $0 / 350(0.0)$ & $0 / 132(0.0)$ & $11 / 344(3.2)$ & 6/182 (3.3) \\
\hline Trauma & $1 / 402(0.2)$ & $0 / 166(0.0)$ & $2 / 350(0.6)$ & $0 / 132(0.0)$ & $31 / 344(9.0)$ & $11 / 182(6.0)$ \\
\hline Recent hospitalization (<3 months) & $26 / 401(6.5)$ & 18/165 (10.9) & $41 / 348(11.8)$ & $31 / 131(23.7)$ & $90 / 342(26.3)$ & $58 / 182(31.9)$ \\
\hline Recent antibiotic treatment ( $<3$ months) & $50 / 402(12.4)$ & 24/165 (14.5) & $56 / 347(16.1)$ & $39 / 130(30.0)$ & $56 / 342(16.4)$ & $47 / 182(25.8)$ \\
\hline \multicolumn{7}{|l|}{ Causes for ICU admission } \\
\hline Shock & $58 / 394(14.7)$ & $44 / 163(27.0)$ & $144 / 343(42.0)$ & $66 / 127(52.0)$ & $147 / 336(43.8)$ & $97 / 179(54.2)$ \\
\hline Acute respiratory failure & $371 / 401(92.5)$ & 150/166 (90.4) & $316 / 349(90.5)$ & 117/131 (89.3) & 196/334 (58.7) & $83 / 179(46.4)$ \\
\hline ARDS & $271 / 398(68.1)$ & $115 / 165(69.7)$ & $157 / 342(45.9)$ & $63 / 127(49.6)$ & $44 / 330(13.3)$ & 28/179 (15.6) \\
\hline Neurological failure & 13/385 (3.4) & 13/163 (8.0) & $51 / 339(15.0)$ & 18/126 (14.3) & 128/331 (38.7) & $63 / 178(35.4)$ \\
\hline Cardiac arrest & $1 / 384(0.3)$ & $2 / 163(1.2)$ & $14 / 338(4.1)$ & $11 / 127(8.7)$ & $40 / 329(12.2)$ & $44 / 179(24.6)$ \\
\hline Acute kidney injury & $48 / 385(12.5)$ & $48 / 163(29.4)$ & $84 / 337(24.9)$ & 49/124 (39.5) & $87 / 327(26.6)$ & $49 / 178(27.5)$ \\
\hline
\end{tabular}

Values are as no./No. (\%) or median (interquartile range)

McCabe classification of comorbidities and likelihood of survival, likely to survive $>5$ years, $1-5$ years, $<1$ year; Chronic renal failure, KDOQI CKD classification stage 4 or 5 (creatinine clearance $<30 \mathrm{ml} / \mathrm{mn}$ ); Chronic heart failure, NYHA class III or IV; Heart disease, ischemic heart disease or atrial fibrillation; Cirrhosis, Child-Pugh score B or $\mathrm{C}$; Immunosuppression if haematological malignancy, allogenic stem cell transplant, organ transplant, HIV or immunosuppressive drugs; More than one cause for ICU admission is possible

${ }^{\mathrm{a}} 1$ missing value in influenza group; ${ }^{\mathrm{b}} 160$ missing values (SARS-CoV-2, $n=32$; influenza, $n=68$; controls, $n=60$ ); ${ }^{\mathrm{c}} 87$ missing values (SARS-CoV-2, $n=43$; influenza, $n=21$; controls, $n=21$ ); ${ }^{\mathrm{d}} 27$ missing values (SARS-CoV-2, $n=21$; influenza, $n=4$; controls, $n=2$ ); ${ }^{\mathrm{e}} 50$ missing values (SARS-CoV-2, $n=19$; influenza, $n=11$; controls, $n=20)$ 
Table 2 Patient characteristics during ICU stay according to disease groups and 28-day mortality

\begin{tabular}{|c|c|c|c|c|c|c|}
\hline & \multicolumn{2}{|c|}{ SARS-CoV-2 pneumonia } & \multicolumn{2}{|c|}{ Influenza pneumonia } & \multicolumn{2}{|l|}{ No viral infection } \\
\hline & Alive $(n=402)$ & Dead $(n=166)$ & Alive $(n=350)$ & Dead $(n=132)$ & Alive $(n=344)$ & Dead $(n=182)$ \\
\hline Antiviral treatment & $226 / 401(56.4)$ & $96 / 165(58.2)$ & $319 / 349(91.4)$ & 118/132 (89.4) & 19/343 (5.5) & $5 / 180(2.8)$ \\
\hline Oseltamivir & $30 / 399(7.5)$ & $14 / 164(8.5)$ & $314 / 344(91.3)$ & 116/131 (88.5) & 18/342 (5.3) & $4 / 179(2.2)$ \\
\hline Remdesivir & 21/399 (5.3) & 6/164 (3.7) & 0/344 (0.0) & 0/131 (0.0) & $0 / 342(0.0)$ & $0 / 179(0.0)$ \\
\hline Lopinavir-Ritonavir & $96 / 399(24.1)$ & $51 / 164(31.1)$ & $0 / 344(0.0)$ & $0 / 131(0.0)$ & $0 / 342(0.0)$ & $0 / 179(0.0)$ \\
\hline Lopinavir-Ritonavir + interferon & 12/399 (3.0) & 9/164 (5.5) & $0 / 344(0.0)$ & $0 / 131(0.0)$ & $0 / 342(0.0)$ & $0 / 179(0.0)$ \\
\hline Hydroxychloroquine & 134/399 (33.6) & $39 / 164(23.8)$ & $0 / 344(0.0)$ & $1 / 131(0.8)$ & $0 / 342(0.0)$ & $0 / 179(0.0)$ \\
\hline Corticosteroids & $131 / 380(34.5)$ & $71 / 162(43.8)$ & $124 / 345(35.9)$ & $58 / 130(44.6)$ & $97 / 343(28.3)$ & $64 / 182(35.2)$ \\
\hline Hydrocortisone & $27 / 377(7.2)$ & $32 / 160(20.0)$ & $64 / 343(18.7)$ & $43 / 130(33.1)$ & $39 / 340(11.5)$ & $41 / 180(22.8)$ \\
\hline Dexamethasone & $32 / 377(8.5)$ & $16 / 160(10.0)$ & $1 / 343(0.3)$ & 0/130 (0.0) & $6 / 340(1.8)$ & $4 / 180(2.2)$ \\
\hline Methylprednisolone & 70/377 (18.6) & 21/160 (13.1) & $58 / 343(16.9)$ & 15/130 (11.5) & $51 / 340(15.0)$ & $17 / 180(9.4)$ \\
\hline Highest daily dose, mga & $100(67-133)$ & $71(50-133)$ & $75(50-100)$ & $50(50-100)$ & $63(50-100)$ & $50(50-75)$ \\
\hline Duration, days ${ }^{b}$ & $6(4-9)$ & $6(4-8)$ & $5(3-9)$ & $6(3-9)$ & $4(2-7)$ & $4(3-8)$ \\
\hline Antibiotic treatment & $363 / 378(96.0)$ & $143 / 153(93.5)$ & $309 / 330(93.6)$ & $125 / 128(97.7)$ & 268/323 (83.0) & 147/173 (85.0) \\
\hline Duration, days & $7(5-9)$ & $7(4-10)$ & $7(5-11)$ & $7(4-9)$ & $7(4-9)$ & $6(4-9)$ \\
\hline Prone positioning & $263 / 401(65.6)$ & $120 / 166(72.3)$ & $96 / 349(27.5)$ & $55 / 132(41.7)$ & $33 / 340(9.7)$ & $30 / 182(16.5)$ \\
\hline ECMO & 39/402 (9.7) & 22/165 (13.3) & 38/349 (10.9) & 22/131 (16.8) & $2 / 341(0.6)$ & $3 / 182(1.6)$ \\
\hline
\end{tabular}

Vales are no./No. (\%) or median (interquartile range)

ECMO, Extracorporeal Membrane Oxygenation; ICU, Intensive Care Unit; MV, Mechanical Ventilation

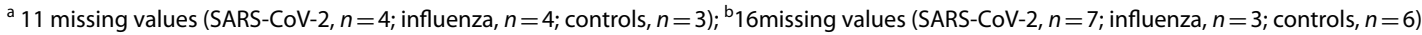

\begin{tabular}{|c|c|c|c|c|c|c|c|}
\hline \multirow{3}{*}{$\begin{array}{l}\text { Outcomes } \\
\text { Overall Survival }\end{array}$} & \multirow{3}{*}{$\begin{array}{l}\text { Comparison groups } \\
\text { SARS-CoV-2 vs. Influenza }\end{array}$} & \multicolumn{2}{|c|}{ Undjusted } & & & \multicolumn{2}{|c|}{ Adjusted } \\
\hline & & \multirow{2}{*}{$\begin{array}{l}\mathrm{HR}(95 \% \mathrm{Cl}) \\
1.08(0.83 \text { to } 1.39)\end{array}$} & \multicolumn{3}{|l|}{ P-Value } & \multirow{2}{*}{$\begin{array}{l}\mathrm{HR}(95 \% \mathrm{Cl}) \\
1.38(1.03 \text { to } 1.84)\end{array}$} & \multirow{2}{*}{$\begin{array}{l}\text { P-Value } \\
0.029\end{array}$} \\
\hline & & & 0.58 & & $\longrightarrow$ & & \\
\hline & SARS-CoV-2 vs. No viral infection & 0.80 (0.59 to 1.08$)$ & 0.14 & & $=$ & 1.21 (0.86 to 1.68$)$ & 0.027 \\
\hline \multirow[t]{2}{*}{ MV duration } & SARS-CoV-2 vs. Influenza & 0.73 (0.60 to 0.90$)$ & $<0.001$ & $\rightarrow$ & & $0.70(0.59$ to 0.83$)$ & $<0.001$ \\
\hline & SARS-CoV-2 vs. No viral infection & 0.61 (0.49 to 0.74$)$ & $<0.001$ & - & & $0.66(0.55$ to 0.80$)$ & $<0.001$ \\
\hline \multirow[t]{7}{*}{ Length of ICU stay } & SARS-CoV-2 vs. Influenza & 0.97 (0.76 to 1.24$)$ & 0.81 & & - & 1.24 (0.93 to 1.63$)$ & 0.14 \\
\hline & SARS-CoV-2 vs. No viral infection & $0.66(0.48$ to 0.91$)$ & 0.009 & & $=$ & $1.10(0.78$ to 1.55$)$ & 0.59 \\
\hline & & \multicolumn{2}{|l|}{0.1} & \multicolumn{2}{|c|}{1.0} & \multicolumn{2}{|c|}{10.0} \\
\hline & & \multicolumn{2}{|l|}{$\longleftarrow$} & \multicolumn{2}{|c|}{ Adjusted $\mathrm{HR}(95 \% \mathrm{Cl})$} & 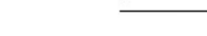 & \\
\hline & & \multicolumn{2}{|l|}{ Favors an increase in } & & & \multicolumn{2}{|c|}{ Favors a decrease in } \\
\hline & & \multicolumn{2}{|l|}{ Survival } & & & $\begin{array}{l}\text { Surviv } \\
\text { My du }\end{array}$ & \\
\hline & & \multicolumn{2}{|l|}{ MV duration } & & & \multicolumn{2}{|c|}{ MV duration } \\
\hline \multicolumn{8}{|c|}{$\begin{array}{l}\text { Fig. } 1 \text { Unadjusted and Adjusted hazard ratios for 28-day mortality, extubation alive and ICU discharge alive, associated with SARS-CoV-2 } \\
\text { pneumonia, versus influenza pneumonia and no viral infection groups. HRs were calculated using cause-specific proportional hazard models, by } \\
\text { considering mortality as competing event for MV duration, and length of ICU stay. Adjusted HRs were calculated, including age, gender, simplified } \\
\text { acute physiology score II, Charlson score, MacCabe classification, shock, and acute respiratory distress syndrome as pre-specified covariates in Cox's } \\
\text { models (after handling missing values by multiple imputation). A HR }>1 \text { indicates a decrease in survival duration (i.e. an increased risk for mortality), } \\
\text { MV duration (i.e. an increased risk for extubation alive) and ICU length of stay (i.e. an increased risk for discharge alive) and a HR< } 1 \text { indicates an } \\
\text { increase in survival duration (i.e. a decreased risk for mortality), MV duration (i.e. a decreased risk for extubation alive) and ICU length of stay (i.e. a } \\
\text { decreased risk for discharge alive). Note that the event of interest for survival is a pejorative event (death) whereas for MV duration and ICU length } \\
\text { of stay, the event of interest is a positive event (extubation or discharge alive). Consequently, the detrimental effect of SARS-CoV-2 pneumonia } \\
\text { (vs influenza pneumonia and no viral infection groups) was associated with a HR }>1 \text { for overall survival but was associated with a HR }<1 \text { for MV } \\
\text { duration and ICU length of stay. HR, hazard ratio; ICU, intensive care unit; MV, mechanical ventilation }\end{array}$} \\
\hline
\end{tabular}


infection was also associated with significantly higher risk for mortality, as compared to influenza group (Fig. 1).

\section{Characteristics of patients with ventilator-associated} pneumonia

Antimicrobial treatment was prescribed to 191 of 205 (93.2\%), 98 of 105 (93.3), and 82 of 87 (94.3) patients with VAP in SARS-CoV-2, influenza, and no viral infection groups; respectively. Initial antibiotic treatment was appropriate in 145 of 200 (72.5\%), 69 of 102 (67.7\%), and 54 of 87 (62.1\%) VAP patients in SARS-CoV-2, influenza, and no viral infection group; respectively. Median (interquartile range) time from starting invasive mechanical ventilation to VAP occurrence was $9(6,13)$ days in SARS-CoV-2, $9(5,13)$ days in influenza, and $7(4,12)$ days in no viral infection groups. Percentage of patients with late-onset VAP was $82.4 \%$ (169 of 200 patients), $73.8 \%$ (79 of 102 patients), and 65.5\% (57 of 87 patients) in SARS-CoV-2, influenza, and no viral infection group; respectively. Pseudomonas aeruginosa, Enterobacter spp., and Klebsiella spp. were the most frequently identified microorganisms (Table 3). Percentage of VAP patients with MDR was lower in SARS-CoV-2 patients as compared to the two other groups, as well as percentage of patients with late-onset VAP related to MDR (35 of 167 patients (21\%), 27 of 78 patients (34.6\%), and 20 of 57 patients (35.1\%), in SARS-CoV-2, influenza, and no viral infection groups; respectively).

\section{Primary and secondary study outcomes}

VAP was associated with higher risk for 28-day mortality in in SARS-CoV-2 group, but not in the two other groups (Fig. 2A). However, the heterogeneity test showed no significant difference in the strength of association between VAP and mortality across the 3 study groups.

VAP was associated with significantly longer duration of mechanical ventilation in the SARS-CoV-2 group, but not in influenza or no viral infection groups. The heterogeneity test showed no significant difference between the 3 groups regarding the association between VAP and duration of mechanical ventilation (Fig. 2B).

VAP was associated with significantly longer duration of ICU stay in all study groups. The heterogeneity test

Table 3 Microorganisms responsible for ventilator-associated pneumonia

\begin{tabular}{|c|c|c|c|}
\hline & SARS-CoV-2 pneumonia $(n=205)$ & Influenza pneumonia $(n=107)$ & $\begin{array}{l}\text { No viral } \\
\text { infection } \\
(n=87)\end{array}$ \\
\hline \multicolumn{4}{|l|}{ Gram-positive cocci } \\
\hline MSSA & $20(9.8)$ & $5(4.7)$ & $8(9.2)$ \\
\hline MRSA & $6(2.9)$ & $4(3.7)$ & $2(2.3)$ \\
\hline Enterococcus spp. & $7(3.4)$ & $2(1.9)$ & $2(2.3)$ \\
\hline Streptococcus pneumoniae & $7(3.4)$ & $1(1)$ & $2(2.3)$ \\
\hline Streptococcus spp. & $1(0.5)$ & $0(0)$ & $0(0)$ \\
\hline Other & $0(0)$ & $2(1.9)$ & $3(3.5)$ \\
\hline \multicolumn{4}{|l|}{ Gram-negative bacilli } \\
\hline Pseudomonas aeruginosa & $51(24.9)$ & $26(24.3)$ & $15(17.2)$ \\
\hline Enterobacter spp. & $37(18)$ & $15(14)$ & $12(13.8)$ \\
\hline Klebsiella spp. & $26(12.7)$ & $17(15.9)$ & $12(13.8)$ \\
\hline Escherichia coli & $19(9.2)$ & $8(7.5)$ & $5(5.7)$ \\
\hline Acinetobacter baumannii & $9(4.4)$ & $16(15)$ & $10(11.5)$ \\
\hline Stenotrophomonas maltophilia & $4(2)$ & $2(1.9)$ & $4(4.6)$ \\
\hline Serratia marcescens & $9(4.4)$ & $4(3.7)$ & $1(1.1)$ \\
\hline Citrobacter freundii & $6(2.9)$ & $1(1)$ & $1(1.1)$ \\
\hline Citrobacter spp. & $5(2.4)$ & $3(2.8)$ & $3(3.5)$ \\
\hline Proteus mirabilis & $5(2.4)$ & $1(1)$ & $2(2.3)$ \\
\hline Haemophilus influenza & $3(1.5)$ & $5(4.7)$ & $5(5.7)$ \\
\hline Morganella morganii & $2(1)$ & $3(2.8)$ & $0(0)$ \\
\hline Other & $26(12.7)$ & $8(7.5)$ & $5(5.7)$ \\
\hline Polymicrobial & $24(11.7)$ & $8(7.5)$ & $6(6.9)$ \\
\hline Multidrug-resistant isolates* & $42(20.7)$ & $42(40)$ & $27(31)$ \\
\hline
\end{tabular}

Data are presented as $N(\%)$

${ }^{*}$ Missing data: 2, 2 in SARS-CoV-2 and Influenza groups; respectively

MRSA, methicillin-resistant Staphylococcus aureus; MSSA, methicillin-sensitive Staphylococcus aureus 


\section{(See figure on next page.)}

Fig. 2 Association between ventilator-associated lower respiratory tract infections and outcomes. a 28-Day mortality. b Duration of mechanical ventilation. $\mathbf{c}$ Length of ICU stay. HRs were calculated using cause-specific proportional hazard models, considering the first VA-LRTI as a time dependent 3-levels categorical variable (No VA-LRTI vs. VAT vs. VAP). Adjusted HRs were calculated including age, gender, simplified acute physiology score II, Charlson score, MacCabe classification, shock, and acute respiratory distress syndrome as pre-specified covariables in Cox's model. Since the event of interest for 28-Day mortality is a pejorative event (death), whereas for MV duration and ICU length of stay, the event of interest is a positive event (extubation or discharge alive), the detrimental effect of SARS-CoV-2 pneumonia (vs influenza pneumonia and no viral infection groups) was associated with a HR $>1$ for 28-Day mortality, with a HR $<1$ for MV duration and ICU length of stay. HR, hazard ratio; ICU, intensive care unit; MV, mechanical ventilation; VA-LRTI, ventilator-associated respiratory tract infection; VAP, ventilator-associated pneumonia; VAT, ventilator-associated tracheobronchitis

showed no significant difference between the 3 groups regarding the association between VAP and ICU length of stay (Fig. 2C).

VAT was not significantly associated with increased risk for mortality, or longer duration of mechanical ventilation in the 3 study groups. VAT was associated with significantly longer ICU stay in no viral infection group, but not in the two other groups. The heterogeneity test was significant between the 3 groups regarding duration of ICU stay (Fig. 2a-c).

Descriptive characteristics and outcomes of patients with, or without, VA-LRTI are presented in Additional file 1: Tables 1, and 2. The association between VA-LRTI and outcomes, according to study groups, is presented in Additional file 1: Fig. 2.

\section{Discussion}

\section{Main results}

The main results of our study are that VAP is associated with increased 28-day mortality rate and longer duration of mechanical ventilation and ICU length of stay in SARS-CoV-2 patients. SARS-CoV-2 infection, compared with influenza or no viral infection, has no significant impact on the relationship between VAP and 28-day mortality, neither on the relationship between VAP and duration of mechanical ventilation, or ICU length of stay. Relationship between VAP and mortality in SARS-CoV-2 patients

Few data are available on mortality rate in SARS-CoV-2 patients with VAP. Although several recent studies evaluated the incidence of VAP in these patients, only one study performed in ARDS patients requiring ECMO [6], reported on mortality rate $(30 \%)$ in this population. However, this study was performed in a single center, the number of patients with SARS-CoV-2 infection was small $(n=50)$, and no comparison was performed with mortality rate in SARS-CoV-2 patients with no VAP.

Previous studies, performed in general ICU populations, showed an increased mortality rate in VAP patients [22-25]. A large meta-analysis was performed on individual data from 6284 patients included in randomized controlled trials of VAP prevention [8]. The overall attributable mortality of VAP was $13 \%$, with higher rates for surgical patients and patients with a mid-range severity score at admission. Attributable mortality was mainly caused by prolonged exposure to the risk of dying due to increased length of ICU stay. However, other studies suggested that mortality attributable to VAP was small $[26$, 27].

\section{Impact of SARS-CoV-2 infection on the relationship between VAP and mortality}

Multidrug resistant bacteria (MDR) bacteria and inappropriate initial antibiotic treatment are well-known risk factors for mortality in VAP patients [28, 29]. Although the incidence of MDR, and inappropriate initial antibiotic treatment was lower in COVID-19 patients, as compared to the two other groups, the relationship between VAP and mortality was only significant in COVID-19 patients. This suggests that SARS-CoV-2 infection and specific pulmonary lesions might play a role in the severity and outcome of VAP in this population. Nevertheless, the absence of significant heterogeneity between the three groups suggests that SARS-CoV-2 infection has no significant impact on the relationship between VAP and mortality. At least three explanations could be provided for this result. First, potential confounders might have influenced our results. However, careful adjustment was performed on SAPS II, age, gender, comorbidities, septic shock, and ARDS, based on the results of prior studies $[13,30]$. Second, the number of patients with VAP was relatively small in the no viral infection group, and the study might have been underpowered to detect a significant effect. Third, SARS-CoV-2 infection could be associated with similar impact on the relationship between VAP and mortality. Previous studies suggested that COVID-19 patients have similar outcomes as other patients with similar type of acute illness. For example, a recent study reported a 90-day mortality rate of $37 \%$ in COVID-19 ARDS [1], which is in line with previous results in non-COVID ARDS [31]. 


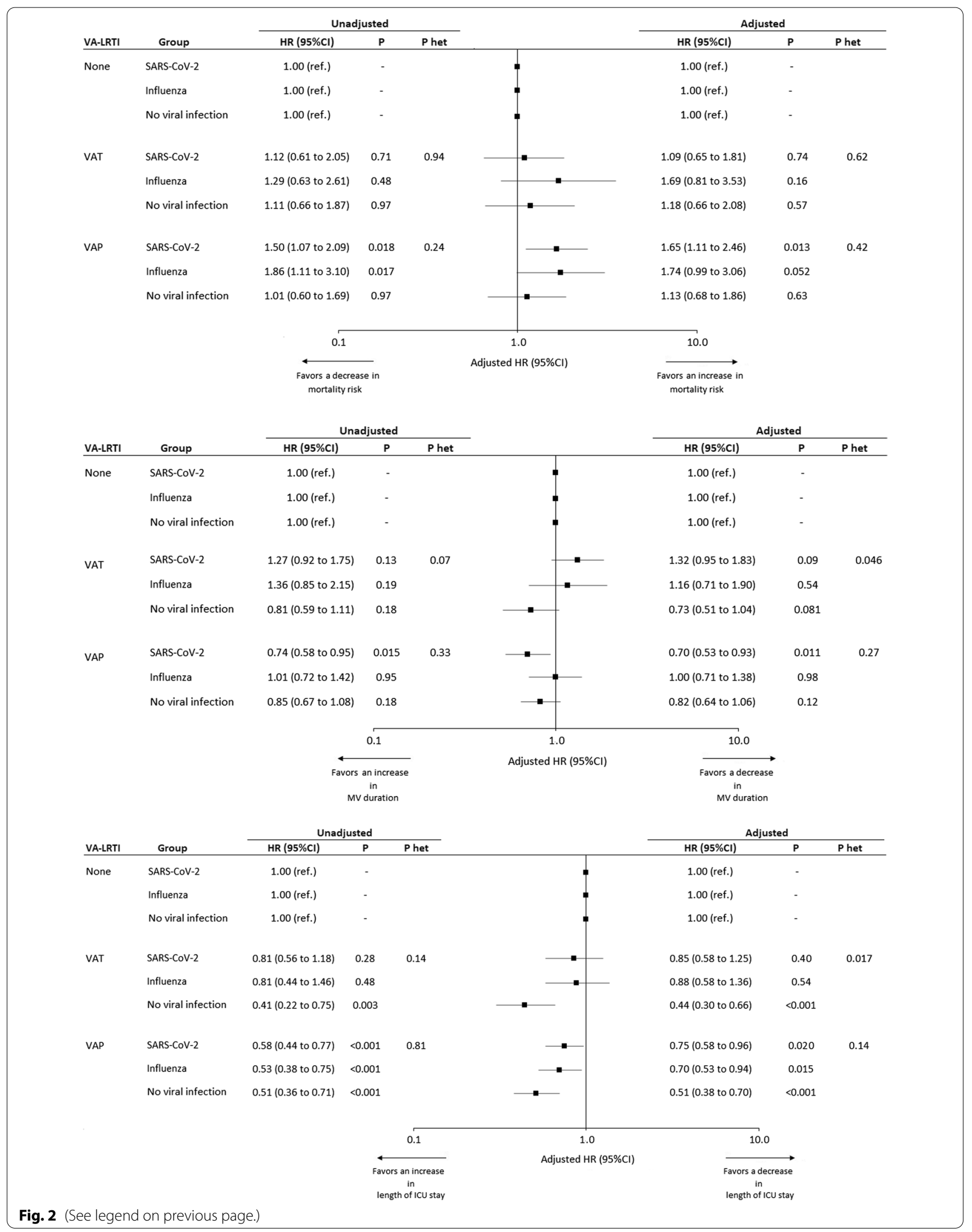




\section{Strengths and limitations}

To our knowledge, our study is the first to evaluate the relationship between VAP and mortality in SARS-CoV-2 patients. Strengths of this study are the large number of included patients, the multicenter design, and the two control groups including patients with influenza pneumonia or no viral infection. In addition, we carefully adjusted for potential confounders, using competing risk analyses, and Kalbfleisch and Prentice methods. Cox's model took into account the immortal time bias, by considering VAP as time-dependent covariable [32]. The discrepancy between the lower mortality rate in SARS-CoV-2 patients with VAP, as compared with those with no VA-LRTI (Additional file 1: Table 2), and the adjusted hazard ratio showing an increased risk for mortality in the former than in the latter group (Fig. $2 \mathrm{~A}$ ) is explained by the immortal time bias in the calculation of actual mortality rate.

Some limitations of this study should be acknowledged. First, coVAPid cohort was retrospective. However, VAP was prospectively identified in all centers. Further, the presence of new infiltrate on chest X-ray was evaluated by at least two physicians. Second, the study was performed in Europe, and the results may not be generalized to other world regions. Third, number of patients was relatively small in some subgroups with VAP or VAT, and our study might have been underpowered to detect differences regarding some secondary outcomes. Fourth, in spite of careful adjustment, our analysis might have missed some residual confounders. Fifth, the interpretation of chest- $x$ ray is a difficult task in patients with pneumonia or ARDS. In spite of evaluation of chest-X ray by at least two physicians to confirm the presence of new infiltrate, some patients with VAP could have been misclassified in the VAT group. Further, some patients with VAT (12.6\%) developed subsequent VAP. However, we repeated the analysis on the relationship between VAP and mortality, including VAT patients and the results did not differ (Additional file 1: Fig. 2). Sixth, no information was collected on timing of appropriate initial antibiotic treatment. Finally, patients were only followed-up until day 28 . Therefore, outcomes at day 60 , or day 90 could not be evaluated.

\section{Conclusions}

To conclude, our results suggest that VAP is associated with increased 28-day mortality rate and longer duration of mechanical ventilation and ICU length of stay in SARS-CoV-2 patients. However, SARS-CoV-2 infection, compared with influenza or no viral infection, has no significant impact on the relationship between VAP and 28-day mortality, or on the relationship between VAP and duration of mechanical ventilation, and ICU length of stay. Further studies are needed to confirm our findings.

\section{Abbreviations}

COVID: Coronavirus disease; HR: Hazard ratio; ICU: Intensive care unit; MV: Mechanical ventilation; SARS-CoV-2: Severe acute respiratory syndrome Coronavirus 2; VA-LRTI: Ventilator-associated respiratory tract infection; VAP: Ventilator-associated pneumonia; VAT: Ventilator-associated tracheobronchitis.

\section{Supplementary Information}

The online version contains supplementary material available at https://doi. org/10.1186/s13054-021-03588-4.

Additional file 1. Online supplementay data.

\section{Acknowledgements}

In addition to the authors, the coVAPid study group includes the following collaborators: Raphaël Favory: CHU de Lille, Centre de Réanimation, F-59000 Lille, France. Sébastien Préau: CHU de Lille, Centre de Réanimation, F-59000 Lille, France. Mercé Jourdain: CHU de Lille, Centre de Réanimation, F-59000 Lille, France. Julien Poissy: CHU de Lille, Centre de Réanimation, F-59000 Lille, France. Piehr Saint Leger: Service de Réanimation polyvalente, Centre Hospitalier de Valenciennes, Valenciennes, France. Thierry Van der Linden: Médecine intensive réanimation, Hôpital Saint Philibert GHICL, Université catholique, Lille, France. Anne Veinstein: CHU de Poitiers, Médecine Intensive Réanimation, CIC 1402 ALIVE, Université de Poitiers, Poitiers, France. Elie Azoulay: Service de médecine intensive et réanimation, hôpital Saint-Louis, 1 Avenue Claude Vellefaux, 75010, Paris, France. Frédéric Pene: Medical Intensive Care Unit, Cochin Hospital, AP-HP. Centre, \& Université de Paris, Paris, France. Maelle Martin: Service de Médecine Intensive Réanimation, CHU de Nantes, Nantes, France. Keyvan Razazi: Assistance Publique-Hôpitaux de Paris, CHU Henri Mondor, Service de réanimation médicale, Créteil, France. Gaëtan Plantefeve: Réanimation Polyvalente, CH Victor Dupouy, Argenteuil, France. Muriel Fartoukh: Sorbonne Université, Assistance Publique-Hôpitaux de Paris, Service de Médecine Intensive Réanimation, Hôpital Tenon, Paris, France. Didier Thevenin: Réanimation polyvalente CH Lens, France. Bertrand Guidet: Service de Médecine Intensive Réanimation, AP-HP, Hôpital Saint-Antoine, Assistance Publique-Hôpitaux de Paris, 184 rue du Faubourg Saint-Antoine, Paris, 75571 Cedex 12, France. Nicolas Weiss: Sorbonne Université, AP-HP, Hôpital de la Pitié-Salpêtrière, Département de Neurologie, Unité de Médecine Intensive Réanimation Neurologique, Paris, France. Achille Kouatchet: Département de Médecine Intensive-Réanimation, CHU d'Angers, Université d'Angers, 4 rue Larrey, 49933, Angers Cedex 9, France. Charlotte Salmon: Service de Médecine Intensive Réanimation, CHU de Tours, Hôpital Bretonneau, 2 Bd Tonnellé, 37000 Tours, France. Guillaume Brunin: Service de réanimation, hôpital Duchenne, rue Monod, 62200 Boulogne-sur-Mer, France. Safaa Nemlaghi: Service de Pneumologie, Médecine intensive - Réanimation (Département "R3S"), AP-HP, Sorbonne Université, Groupe Hospitalier Universitaire Pitié-Salpêtrière Charles Foix, 75013, Paris, France. David Meguerditchian: Intensive Care Unit, Pellegrin-Tripode Hospital, University Hospital of Bordeaux, Bordeaux, France. Laurent Argaud: Service de Médecine Intensive - Réanimation, Hospices Civils de Lyon, Hôpital Edouard Herriot, 5, place d'Arsonval, 69437, Lyon Cedex 03, France. Sebastian Voicu: Réanimation Médicale et Toxicologique, Hôpital Lariboisière, Université de Paris, INSERM UMRS-1144, Paris, France. Charles-Edouard Luyt: Service de Médecine Intensive Réanimation, Institut de Cardiologie, Hôpital Pitié-Salpêtrière, Assistance Publique-Hôpitaux de Paris (APHP), Sorbonne Université, 47-83, Boulevard de l'Hôpital, 75651, Paris Cedex 13, France. Benjamin Kowalski: Service de réanimation et de soins intensifs, centre hospitalier de Douai, route de Cambrai, Douai, France. Edgar Moglia: Critical Care Department, Hospital Universitari Parc Taulí, Sabadell, Spain. Luis Morales: Intensive Care Unit, Hospital Universitari Sagrat Cor, and Universidad Autonoma de Barcelona, Barcelona, Spain Intensive Care Unit, Hospital Unive rsitari Sagrat Cor, Barcelona, Spain; Institut d'Investigacio i Innovacio Parc Tauli, Sabadell, Spain. Antonia Koutsoukou: 1st Department of Pulmonary Medicine and Intensive Care Unit, National and Kapodistrian University of Athens,

"Sotiria" Chest Hospital, Athens, Greece. Spyros D. Mentzelopoulos: 1st Department of Intensive Care Medicine, National and Kapodistrian University of Athens Medical School, Evaggelismos Hospital, Athens, Greece. David Nora: Polyvalent Intensive Care Unit, São Francisco Xavier Hospital, Centro Hospitalar de Lisboa Ocidental, Lisbon, Portugal. Sean Boyd: 3Department of Intensive Care Medicine, Multidisciplinary Intensive Care Research Organization (MICRO), 
St. James's Hospital, St. James Street, Dublin 8, Dublin, Eire, Ireland. Julien Maizel: Medical ICU, Amiens university hospital, Amiens, France. Pierre Cuchet: Department of Medical Intensive Care, Caen University Hospital, F-14000 Caen, France. Quentin Delforge: Service de Médecine Intensive Réanimation, Centre hospitalier de Béthune. Jean-Pierre Quenot: Department of Intensive Care, François Mitterrand University Hospital, Dijon, France. Déborah Boyer: 42Medical Intensive Care Unit, Rouen University Hospital, Rouen, France. Catia Cilloniz: Pulmonology Department, Hospital Clinic of Barcelona, Ciber de Enfermedades Respiratorias (Ciberes, CB06/06/0028)-Institut d'Investigacions Biomèdiques August Pi i Sunyer (IDIBAPS), Barcelona, Spain.

\section{Authors' contributions}

$A R$, IML, PP, JL, AD, and SN designed the study. $J L$, and $A D$ performed the statistical analyses. All authors collected study data. The first draft was written by SN, and AR. All authors participated in writing, and revising the manuscript.

\section{Funding}

This study was supported in part by a grant from the French government through the «Programme Investissement d'Avenir» (I-SITE ULNE) managed by the Agence Nationale de la Recherche (coVAPid project). The funders of the study had no role in the study design, data collection, analysis, or interpretation, writing of the report, or decision to submit for publication.

\section{Availability of data and materials}

All data needed to evaluate the conclusions in this Article are present and tabulated in the main text or the appendix. This article is the result of an original retrospective cohort. For individual de-identified raw data that underlie the results reported in this article, please contact the corresponding author.

\section{Declarations}

\section{Ethics approval and consent to participate}

The Ethics Committee, and Institutional Review Boards approved the study protocol (Comité de Protection des Personnes Ouest Vl; approved by April 14 2020; registration number RIPH:20.04.09.60039) as minimal-risk research using data collected for routine clinical practice, and waived the requirement for informed consent.

\section{Consent for publication}

Not applicable.

\section{Competing interests}

$A R$ received personal fees from MaatPharma, IML received personal fees from MSD, and Gilead. AA received personal fees from Lilly Foundation, and grants from Grifols and Fischer \& Paykel. CEL received personal fees from Bayer, Merck, Aerogen, Biomérieux, ThermoFischer Brahms, and Carmat. SN received personal fees from MSD, Bio Rad, BioMérieux, Gilead, and Pfizer. All other authors declare no competing interests.

\section{Author details}

${ }^{1}$ Médecine Intensive-Réanimation, CHU de Lille, F-59000 Lille, France. ${ }^{2}$ Inserm U1285, CNRS, UMR 8576-UGSF-Unité de Glycobiologie Structurale et Fonctionnelle, Univ. Lille, Lille, France. ${ }^{3}$ Department of Intensive Care Medicine, Multidisciplinary Intensive Care Research Organization (MICRO), St. James's Hospital, St. James Street, Dublin 8, Dublin, Eire, Ireland. ${ }^{4}$ Hospital Clinic, IDIBAPS, Universided de Barcelona, CIBERes, Barcelona, Spain. ${ }^{5}$ Polyvalent Intensive Care Unit, São Francisco Xavier Hospital, Centro Hospitalar de Lisboa Ocidental, and NOVA Medical School, CHRC, New University of Lisbon, Lisbon, Portugal. ${ }^{6}$ Center for Clinical Epidemiology and Research Unit of Clinical Epidemiology, OUH Odense University Hospital, Odense, Denmark. ${ }^{7}$ Medical ICU, Amiens University Hospital, Amiens, France. ${ }^{8}$ Department of Medical Intensive Care, Caen University Hospital, 14000 Caen, France. ${ }^{9}$ Service de Réanimation Polyvalente, Centre Hospitalier de Valenciennes, Valenciennes, France. ${ }^{10}$ Medical Intensive Care Unit, Rouen University Hospital, Normandie Université, UNIROUEN, Inserm U1096, FHU-REMOD-VHF, 76000 Rouen, France. ${ }^{11}$ Department of Intensive Care, François Mitterrand University Hospital, Dijon, France. ${ }^{12}$ Intensive Care Unit, University Hospital of Larissa, University of Thessaly, 41110 Biopolis Larissa, Greece. ${ }^{13}$ Service de Réanimation Et de Soins Intensifs, Centre Hospitalier de Douai, Route de Cambrai, Douai, France.

${ }^{14}$ Service de Médecine Intensive Réanimation, Institut de Cardiologie, Hôpital
Pitié-Salpêtrière, Assistance Publique-Hôpitaux de Paris (APHP), Sorbonne Université, 47-83, Boulevard de L'Hôpital, 75651 Paris Cedex 13, France. ${ }^{15} \mathrm{ICU}$, Roubaix Hospital, Roubaix, France. ${ }^{16}$ Médecine Intensive Réanimation, Hôpital Saint Philibert GHICL, Université Catholique, Lille, France. ${ }^{17}$ Réanimation Médicale Et Toxicologique, Hôpital Lariboisière, Université de Paris, INSERM UMRS1144, Paris, France. ${ }^{18}$ Service de Médecine Intensive Et Réanimation, Hôpital Saint-Louis, 1 Avenue Claude Vellefaux, 75010 Paris, France. ${ }^{19} \mathrm{Critical}$ Care Department, Hospital Universitari Parc Taulí, Sabadell, Spain. ${ }^{20} 1$ St Department of Intensive Care Medicine, National and Kapodistrian University of Athens Medical School, Evaggelismos Hospital, Athens, Greece. ${ }^{21}$ Medical Intensive Care Unit, Cochin Hospital, AP-HP. Centre, Université de Paris, Paris, France. ${ }^{22}$ Department of Pulmonology, Hospital Clinic Barcelona, University of BarceIona, IDIBAPS, CIBERES, ICREA, Barcelona, Spain. ${ }^{23} 1$ St Department of Pulmonary Medicine and Intensive Care Unit, National and Kapodistrian University of Athens, "Sotiria" Chest Hospital, Athens, Greece. ${ }^{24}$ Réanimation Polyvalente, $\mathrm{CH}$ Lens, Lens, France. ${ }^{25}$ Service de Médecine Intensive Réanimation, CHU de Nantes, Nantes, France. ${ }^{26}$ Service de Médecine Intensive Réanimation, CHU de Tours, Hôpital Bretonneau, 2 Bd Tonnellé, 37000 Tours, France. ${ }^{27}$ Service de Médecine Intensive - Réanimation, Hospices Civils de Lyon, Hôpital Edouard Herriot, 5, place d'Arsonval, 69437 Lyon Cedex 03, France. ${ }^{28}$ Service de Médecine Intensive Réanimation, AP-HP, Hôpital Saint-Antoine, Assistance Publique-Hôpitaux de Paris, 184 rue du Faubourg Saint-Antoine, 75571 Paris Cedex 12, France. ${ }^{29}$ Sorbonne Université, Assistance Publique-Hôpitaux de Paris, Service de Médecine Intensive Réanimation, Hôpital Tenon, Paris, France. ${ }^{30}$ Réanimation Polyvalente, CH Victor Dupouy, Argenteuil, France. ${ }^{31}$ Service de Pneumologie, Médecine Intensive - Réanimation (Département "R3S"), AP-HP, Sorbonne Université, Groupe Hospitalier Universitaire Pitié-Salpêtrière Charles Foix, INSERM, UMRS1158 Neurophysiologie Respiratoire Expérimentale Et Clinique, Paris, France. ${ }^{32}$ Département de Médecine Intensive-Réanimation, CHU D'Angers, Université D'Angers, 4 rue Larrey, 49933 Angers Cedex 9, France. ${ }^{33}$ Intensive Care Unit, Pellegrin-Tripode Hospital, University Hospital of Bordeaux, Bordeaux, France. ${ }^{34} \mathrm{CHU}$ de Poitiers, Médecine Intensive Réanimation, CIC 1402 ALIVE, Université de Poitiers, Poitiers, France. ${ }^{35}$ APHP, CHU Henri Mondor, Service de Médecine Intensive RéanimationUniversité Paris Est-Créteil, Faculté de Santé, Groupe de Recherche Clinique CARMASINSERM U955, Institut Mondor de Recherche Biomédicale, 94010 Créteil, France. ${ }^{36}$ Service de Médecine Intensive Réanimation, Centre Hospitalier de Béthune, Réseau de Recherche Boréal, 62408 Béthune, France. ${ }^{37}$ Service de Réanimation, Hôpital Duchenne, Rue Monod, 62200 Boulogne-sur-Mer, France. ${ }^{38}$ Sorbonne Université, AP-HP, Hôpital de La Pitié-Salpêtrière, Département de Neurologie, Unitéde Médecine Intensive Réanimation Neurologique, Paris, France. ${ }^{39}$ Intensive Care Unit, Hospital Universitari Sagrat Cor, and Ciber de Enfermedades Respiratorias (Ciberes, CB06/06/0028)-Institut D'Investigacions Biomèdiques August Pi I Sunyer (IDIBAPS), Barcelona, Spain. ${ }^{40}$ Critical Care Center, Corporacion Sanitaria Universitaria Parc Tauli, CIBER Enfermedades Respiratorias, Autonomous University of Barcelona, Parc Tauli 1, 08028 Sabadell, Spain. ${ }^{41}$ Univ. Lille, CHU Lille, ULR 2694-METRICS: Évaluation Des Technologies de Santé Et Des Pratiques Médicales, 59000 Lille, France.

Received: 22 February 2021 Accepted: 27 April 2021 Published online: 25 May 2021

\section{References}

1. COVID-ICU Group on behalf of the REVA Network and the COVID-ICU Investigators. Clinical characteristics and day-90 outcomes of 4244 critically ill adults with COVID-19: a prospective cohort study. Intensive Care Med. 2021;47:60-73.

2. Rouzé A, Martin-Loeches I, Povoa P, Makris D, Artigas A, Bouchereau M, Lambiotte F, Metzelard M, Cuchet P, Boulle Geronimi C, Labruyere M, Tamion F, Nyunga M, Luyt C-E, Labreuche J, Pouly O, Bardin J, Saade A, Asfar P, Baudel J-L, Beurton A, Garot D, loannidou I, Kreitmann L, Llitjos J-F, Magira E, Mégarbane B, Meguerditchian D, Moglia E, Mekontso-Dessap $A$, et al. Relationship between SARS-CoV-2 infection and the incidence of ventilator-associated lower respiratory tract infections: a European multicenter cohort study. Intensive Care Med. 2021;47:188-98.

3. Maes M, Higginson E, Pereira-Dias J, Curran MD, Parmar S, Khokhar F, Cuchet-Lourenço D, Lux J, Sharma-Hajela S, Ravenhill B, Hamed I, Heales L, Mahroof R, Solderholm A, Forrest S, Sridhar S, Brown NM, Baker S, Navapurkar V, Dougan G, Bartholdson Scott J, Conway Morris A. 
Ventilator-associated pneumonia in critically ill patients with COVID-19. Crit Care. 2021:25:25.

4. Pickens CO, Gao CA, Cuttica M, Smith SB, Pesce L, Grant R, Kang M, Morales-Nebreda L, Bavishi AA, Arnold J, Pawlowski A, Qi C, Budinger GS, Singer BD, Wunderink RG, Investigators for the NC. Bacterial superinfection pneumonia in SARS-CoV-2 respiratory failure. medRxiv 2021:2021.01.12.20248588.

5. Razazi K, Arrestier R, Haudebourg AF, Benelli B, Carteaux G, Decousser J, Fourati S, Woerther PL, Schlemmer F, Charles-Nelson A, Botterel F, de Prost N, Mekontso Dessap A. Risks of ventilator-associated pneumonia and invasive pulmonary aspergillosis in patients with viral acute respiratory distress syndrome related or not to Coronavirus 19 disease. Crit Care. 2020:24:699.

6. Luyt C-E, Sahnoun T, Gautier M, Vidal P, Burrel S, Pineton de Chambrun M, Chommeloux J, Desnos C, Arzoine J, Nieszkowska A, Bréchot N, Schmidt M, Hekimian G, Boutolleau D, Robert J, Combes A, Chastre J. Ventilatorassociated pneumonia in patients with SARS-CoV-2-associated acute respiratory distress syndrome requiring ECMO: a retrospective cohort study. Ann Intensive Care. 2020;10:158.

7. Llitjos J-F, Bredin S, Lascarrou J-B, Soumagne T, Cojocaru M, Leclerc M, Lepetit A, Gouhier A, Charpentier J, Piton G, Faron M, Stoclin A, Pène F. Increased susceptibility to intensive care unit-acquired pneumonia in severe COVID-19 patients: a multicentre retrospective cohort study. Ann Intensive Care. 2021;11:20

8. Melsen WG, Rovers MM, Groenwold RHH, Bergmans DCJJ, Camus $C$, Bauer TT, Hanisch EW, Klarin B, Koeman M, Krueger WA, Lacherade JC, Lorente L, Memish ZA, Morrow LE, Nardi G, van Nieuwenhoven CA, O'Keefe GE, Nakos G, Scannapieco FA, Seguin P, Staudinger T, Topeli A, Ferrer M, Bonten MJM. Attributable mortality of ventilator-associated pneumonia: a meta-analysis of individual patient data from randomised prevention studies. Lancet Infect Dis. 2013;13:665-71.

9. Safdar N, Dezfulian C, Collard HR, Saint S. Clinical and economic consequences of ventilator-associated pneumonia: a systematic review. Crit Care Med. 2005;33:2184-93.

10. Nseir S, Di Pompeo C, Soubrier S, Cavestri B, Jozefowicz E, Saulnier F, Durocher A. Impact of ventilator-associated pneumonia on outcome in patients with COPD. Chest. 2005;128:1650-6.

11. Rouzé A, Boddaert P, Martin-Loeches I, Povoa P, Rodriguez A, Ramdane N, Salluh J, Houard M, Nseir S. Impact of chronic obstructive pulmonary disease on incidence, microbiology and outcome of ventilator-associated lower respiratory tract infections. Microorganisms. 2020;8:165.

12. Robba C, Rebora P, Banzato E, Wiegers EJA, Stocchetti N, Menon DK, Citerio G. Collaborative European NeuroTrauma effectiveness research in traumatic brain injury participants and investigators: incidence, risk factors, and effects on outcome of ventilator-associated pneumonia in patients with traumatic brain injury: analysis of a large, multicenter, prospective, observational longitudinal study. Chest. 2020;158:2292-303.

13. Papazian L, Klompas M, Luyt C-E. Ventilator-associated pneumonia in adults: a narrative review. Intensive Care Med. 2020;46:888-906.

14. Martin-Loeches I, Povoa P, Rodríguez A, Curcio D, Suarez D, Mira J-PJ-PJ-P, Cordero MLML, Lepeca R, Girault C, Candeias C, Seguin P, Paulino C, Messika J, Castro AGAGAG, Valles J, Coelho L, Rabello L, Lisboa T, Collins D, Torres A, Salluh J, Nseir S, Fernández RO, Arroyo J, Gabriela M, Alvarez R, Reyes AT, Dellera C, Molina F, Franco DM, et al. Incidence and prognosis of ventilator-associated tracheobronchitis (TAVeM): a multicentre, prospective, observational study. Lancet Respir Med. 2015;3:859-68.

15. Guidelines for the management of adults with hospital-acquired. ventilator-associated, and healthcare-associated pneumonia. Am J Respir Crit Care Med. 2005;171:388-416.

16. Paul M, Shani V, Muchtar E, Kariv G, Robenshtok E, Leibovici L. Systematic review and meta-analysis of the efficacy of appropriate empiric antibiotic therapy for sepsis. Antimicrob Agents Chemother. 2010;54:4851-63.
17. Austin PC, Lee DS, Fine JP. Introduction to the analysis of survival data in the presence of competing risks. Circulation. 2016;133:601-9.

18. Therneau T-M, Grambsch P-M. Modeling survival data: extending the Cox model. New-York: Springer; 2000.

19. Willke RJ, Zheng Z, Subedi P, Althin R, Mullins CD. From concepts, theory, and evidence of heterogeneity of treatment effects to methodological approaches: a primer. BMC Med Res Methodol. 2012;12:185.

20. van Burren S, Groothuis-Oudshoorn K. Multivariate imputation by chained equations in R. 2011. J Stat Softw 2011:45:1-24.

21. Gladitz J, Rubin DB. Multiple imputation for nonresponse in surveys. Biom J. 1989;31:131-2

22. Makris D, Desrousseaux B, Zakynthinos E, Durocher A, Nseir S. The impact of COPD on ICU mortality in patients with ventilator-associated pneumonia. Respir Med. 2011;105:1022-9.

23. Bercault N, Boulain T. Mortality rate attributable to ventilator-associated nosocomial pneumonia in an adult intensive care unit: a prospective case-control study. Crit Care Med. 2001;29:2303-9.

24. Martin-Loeches I, Povoa P, Rodríguez A, Curcio D, Suarez D, Mira J-P, Cordero ML, Lepecq R, Girault C, Candeias C, Seguin P, Paulino C, Messika J, Castro AG, Valles J, Coelho L, Rabello L, Lisboa T, Collins D, Torres A, Salluh J, Nseir S. Incidence and prognosis of ventilator-associated tracheobronchitis (TAVeM): a multicentre, prospective, observational study. Lancet Respir Med. 2015;3:859-68.

25. Melsen WG, Rovers MM, Bonten MJM. Ventilator-associated pneumonia and mortality: a systematic review of observational studies. Crit Care Med. 2009;37:2709-18.

26. Bekaert M, Timsit JF, Vansteelandt S, Depuydt P, Vésin A, Garrouste-Orgeas M, Decruyenaere J, Clec'h C, Azoulay E, Benoit D. Attributable mortality of ventilator-associated pneumonia: a reappraisal using causal analysis. Am J Respir Crit Care Med. 2011;184:1133-9.

27. Steen J, Vansteelandt S, De Bus L, Depuydt P, Gadeyne B, Benoit DD, Decruyenaere J. Attributable mortality of ventilator-associated pneumonia: replicating findings, revisiting methods. Ann Am Thorac Soc. 2021;18(5):830-7.

28. Barbier F, Lisboa T, Nseir S. Understanding why resistant bacteria are associated with higher mortality in ICU patients. Intensive Care Med. 2016;42(12):2066-9.

29. Martin-Loeches I, Torres A, Povoa P, Zampieri FG, Salluh J, Nseir S, Ferrer M, Rodriguez A. TAVeM study Group: the association of cardiovascular failure with treatment for ventilator-associated lower respiratory tract infection. Intensive Care Med. 2019;45:1753-62.

30. Nair GB, Niederman MS. Ventilator-associated pneumonia: present understanding and ongoing debates. Intensive Care Med. 2014;41:34-48.

31. Papazian L, Forel J-M, Gacouin A, Penot-Ragon C, Perrin G, Loundou A, Jaber S, Arnal J-M, Perez D, Seghboyan J-M, Constantin J-M, Courant P, Lefrant J-Y, Guérin C, Prat G, Morange S, Roch A. ACURASYS Study Investigators: neuromuscular blockers in early acute respiratory distress syndrome. N Engl J Med. 2010;363:1107-16.

32. Shintani AK, Girard TD, Eden SK, Arbogast PG, Moons KGM, Ely EW. Immortal time bias in critical care research: application of timevarying Cox regression for observational cohort studies. Crit Care Med. 2009:37:2939-45

\section{Publisher's Note}

Springer Nature remains neutral with regard to jurisdictional claims in published maps and institutional affiliations. 